\title{
LA ORDEN DE LA MERCED EN EL SEÑORÍO DE VIZCAYA: EL CASO DEL BEATERIO DE SANTURCE
}

\author{
POR
}

\author{
NERE JONE INTXAUSTEGI JAUREGI ${ }^{1}$ \\ Universidad de Deusto
}

\section{RESUMEN}

Este artículo tiene como objetivo estudiar el beaterio mercedario de Santurce. Para ello se va a realizar un estudio general de los beaterios y conventos femeninos que han existido en el territorio vizcaíno para, después, centrarnos en el caso concreto del de Santurce. La relevancia de esta comunidad de religiosas reside en el hecho de que perduró hasta el siglo XIX sin haber abrazado la clausura.

PALABRAS CLAVE: beaterio; mujeres; Orden de la Merced; Santurce; Vizcaya.

\section{THE ORDER OF THE BLESSED VIRGIN MARY OF MERCY IN BISCAY: THE CASE OF THE BEATERIO OF SANTURCE}

\author{
ABSTRACT \\ $\begin{array}{ll}\text { Recibido/Received } & 17-09-2017 \\ \text { Aceptado/Accepted } & 19-04-2018\end{array}$
}

This paper is focused on the study of the Mercy beaterio of Santurce. Therefore, firstly there is a general study of beaterios and female convents that have existed in Biscay. Secondly, it is studied the concrete case of this beaterio. This religious community is important since it lasted until 19th century without having embraced the closure.

KEY WORDS: beaterio; Biscay; Order of the Blessed Virgin Mary of Mercy; Santurce; women.

Cómo CITAR ESTE ARTículo / CITATION: Intxaustegi Jauregi, N. J. 2019. «La Orden de la Merced en el Señorío de Vizcaya: el caso del beaterio de Santurce». Hispania Sacra 71, 143: 271-282. https://doi.org/10.3989/hs.2019.020

\section{La ORden de la Merced en VizCAYa: los beaterios}

El 10 de agosto de 1218 se constituyó oficialmente la Orden Religiosa Redentora de Cautivos, es decir, la Orden de Santa María de la Merced, en la catedral de la Santa Cruz de Barcelona siendo Pedro Nolasco su fundador. ${ }^{2}$ La orden tuvo una expansión importante y así para el año 1384 su influencia llegó al Señorío de Vizcaya, donde se erigió el convento de los mercedarios de Santa María de Burceña, fundación realizada por el linaje de la Casa de Ayala. ${ }^{3}$ Este convento, que estaba situado en Baracaldo, fue el primer convento mercedario del País Vasco y fue fundado por el conde Fernán Pérez de Ayala y su hijo quienes entregaron

\footnotetext{
1 nere.intxaustegi@deusto.es /

ORCID iD: https://orcid.org/0000-0001-8940-7875

2 Biblioteca Mercedaria 1977: 28.

3 García Fernández 2007: 117.
}

a la Orden de la Merced la iglesia de Santa María con sus bienes y rentas. ${ }^{4}$ Además, Fernán Pérez de Ayala también fundó el convento femenino de las dominicas de Quejana, en Álava. ${ }^{5}$ No hay que perder de perspectiva que en aquellas centurias un convento fue mucho más que un lugar de oración, ya que era visto como un instrumento de poder, un elemento de dominación, una herramienta al servicio de los intereses de los fundadores. Básicamente, se trataba de legitimar y perpetuar el estatus privilegiado y de poder, vinculándose a la dimensión sacra, ${ }^{6}$ algo que obviamente Fernán Pérez de Ayala logró al fundar no uno, sino dos conventos. ${ }^{7}$ Cabe decir que, además de ser conocido por

\footnotetext{
4 Laka Kortabitarte 2002: 458-460.

5 Paz Moro 2017: 35.

6 Atienza López 2008: 16.

7 Más información sobre fundaciones conventuales vascas en Intxaustegi Jauregi 2018b.
} 
sus fundaciones, también lo es por haber sido el padre del Canciller Mayor de Castilla, Pedro López de Ayala. ${ }^{8}$

Al amparo de este convento de Burceña, florecieron pronto unos cuantos beaterios, ${ }^{9}$ los cuales acabaron incorporándose a la espiritualidad de la Orden mercedaria. El mundo de las beatas y de los beaterios ha recibido, por lo general, poca atención por la historiografía, ${ }^{10}$ por lo que, a pesar de estudios varios, sigue siendo un ente desconocido dentro de la disciplina histórica. En el caso vasco, este vacío historiográfico es todavía más acentuado, algo que contrasta con el peso que los beaterios tuvieron en la sociedad vasca, ${ }^{11}$ ya que las beatas fueron una realidad innegable en el País Vasco, donde no ha habido municipio vasco reseñable que no haya acogido algún beaterio. ${ }^{12}$ Un buen reflejo de esta coyuntura lo encontramos en la escasa presencia conventual que hubo en el País Vasco, donde hasta el siglo XVI sólo existieron seis conventos femeninos: cuatro en Álava, situados en Barría, Vitoria, Quejana y Salinas de Añana, el de San Bartolomé en San Sebastián y el de las dominicas vizcaínas de Lequeitio. ${ }^{13}$

El fenómeno de las beatas vascas, a las que también podemos llamar mujeres semi-religiosas, es equiparable a las italianas pinzocchere o las holandesas beguines, ${ }^{14}$ quienes nacieron como consecuencia de los nuevos movimientos religiosos que convulsionaron Europa desde el siglo XIII. ${ }^{15}$ Se desconoce cuándo empezaron a existir beaterios en el País Vasco, pero se tiene constancia que para el siglo XIII ya existían algunos, como era el de San Julián de Orduña que acabó convirtiéndose en el convento de Santa Clara; concretamente, estas beatas, el 10 de noviembre de 1296, recibieron una bula papal de Bonifacio VIII. ${ }^{16}$ Estamos ante comunidades formadas por mujeres que se juntaban para vivir y atender sus inquietudes espirituales, pero siempre bajo un signo altruista. Además, hay que señalar que no había uniformidad de fines, medios o modos. ${ }^{17}$ Los beaterios han de ser vistos como espacios de libertad en la religiosidad no reglada, donde se vivía una existencia religiosa muy extrema a la par que voluntaria, y donde las beatas no eran controladas por normas patriarcales. ${ }^{18}$ Sin embargo, no todos los beaterios se dedicaron en exclusiva a la vida contemplativa ya que realizaban actividades diversas como la asistencia a los enfermos, la catequesis, o se convirtieron en refugio de jóvenes sin dote. ${ }^{19}$ Como recoge Ángela Atienza, una de las primeras cuestiones que hay que tener en cuenta al tratar a las beatas es la variedad de situaciones y de circunstancias que se dieron. ${ }^{20} \mathrm{El}$ nacimiento de estas comunidades hay que verlo como un proceso espontáneo, hecho que motiva que apenas existiera reglamentación

\footnotetext{
8 García Fernández 1995: 217.

9 Ledesma 1709.

10 Atienza López 2007: 145.

11 Al respecto, mencionar los artículos de Intxaustegi Jauregi

12 Lizarralde 1918: 592

13 Intxaustegi Jauregi 2018c: 67.

14 Sastre Santos 1996: 290.

15 Van Engen 2008: 19.

16 Archivo Franciscano Ibero-Oriental [AFIO], 619/24.

7 Uribe 1994: 238.

8 Val Valdivieso 2006: 174.

Atienza López 2007: 168.
} 2017a y 2018 a.

20 Ibídem: 146. sobre su funcionamiento. Por otra parte, es necesario decir que a comienzos del siglo XVI estos beaterios no pertenecían a ninguna orden, algo que empezó a cambiar durante la Edad Moderna, cuando empezaron a alinearse bajo una orden; sin embargo, a pesar de ese cambio, su vida apenas varió y siguieron viviendo sin clausura. ${ }^{21}$

La obligatoriedad de la clausura femenina tuvo sus orígenes en la Edad Media, cuando, en el año 1298, el papa Bonifacio VIII lo recogió en el decreto Periculoso. En este escrito se dictaba que, indistintamente de la regla profesada, una monja nunca podría abandonar el convento ni estaría permitida la entrada al mismo de personas desautorizadas. ${ }^{22}$ Hay que decir que este decreto sólo obligaba a las monjas ya que las semi-religiosas no fueron tenidas en cuenta. El Concilio de Trento, en las últimas sesiones celebradas en el año 1563, volvió a tratar el tema y, una vez más, se obligó a su completa imposición, pero otra vez sólo se legisló para las monjas, sin tener en cuenta a las beatas ${ }^{23}$. Las reacciones a la legislación tridentina no se hicieron esperar, y religiosas europeas la rechazaron. Por ejemplo, en España conventos de Zamora, Salamanca, Valladolid, o Barcelona desafiaron su obligatoriedad. ${ }^{24}$ La base de este rechazo era que el enclaustramiento ponía en peligro su modo de vida y su subsistencia ya que se trataba de someterse a unas condiciones mucho más estrictas que aquellas que habían prometido cuando profesaron..$^{25}$ Además, en las sesiones tridentinas no hubo representación femenina, por lo que su imposición fue vista como una injerencia impuesta por la fuerza sin posibilidad alguna de diálogo. ${ }^{26}$ De esta manera, la clausura, la dependencia a los prelados masculinos, y el control económico constituyeron la base de la reforma tridentina. ${ }^{27}$

La respuesta papal ante los problemas surgidos no se hizo esperar y, en el año 1566, Pío V publicó la bula Circa Pastoralis donde se establecía un encerramiento obligatorio para todas las religiosas, fuesen monjas o semi-religiosas. Es decir, esta vez sí se legisló teniendo en cuenta las beatas. Ciertamente, la ofensiva enclaustradora postridentina fue realmente notable, pero como hubo comunidades donde la clausura no fue abrazada, ya que muchas beatas se negaron a ello, no se puede hablar de una aceptación plena de la misma. ${ }^{28}$ Sin embargo, también hay que decir que hubo casos de transformaciones conventuales de beaterios que se presentaron más espontáneas y naturales, y donde parece que las beatas no fueron condicionadas. ${ }^{29}$ Precisamente, la comunidad objeto de estudio en el presente artículo no sólo se mantuvo en contra del encerramiento religioso, sino que al contrario del resto de los beaterios de la Orden de la Merced de Vizcaya y de los restantes vizcaínos, las beatas mercedarias de Santurce no abrazaron la clausura, y la comunidad vivió sin ella hasta su supresión en el siglo XIX.

\footnotetext{
21 Arana 2002: 851.

22 Makowski 1997: 30.

23 Arana 2002: 854.

24 Atienza López 2014: 813.

25 Evangelisti 2007: 6.

26 Prada Camín 2013: 108.

27 Soriano 2000b: 482.

28 Rapley 1990: 41.

29 Atienza López 2008: 96.
} 
TABLA 1

Los beaterios mercedarios vizcaínos

\begin{tabular}{|c|c|c|c|}
\hline Beaterio-Localidad & $\begin{array}{c}\text { Fecha } \\
\text { fundación }\end{array}$ & $\begin{array}{l}\text { Fecha } \\
\text { clausura }\end{array}$ & Información varia \\
\hline La Naja, Bilbao & 1514 & 1621 & $\begin{array}{l}\text { Principal convento } \\
\text { mercedario vasco }\end{array}$ \\
\hline Deusto, Bilbao & 1537 & - & $\begin{array}{l}\text { Unión con las de La } \\
\quad \text { Naja en } 1675\end{array}$ \\
\hline $\begin{array}{l}\text { Nuestra Señora de la } \\
\text { Piedad, Marquina }\end{array}$ & 1547 & 1621 & $\begin{array}{c}\text { Cambio nombre al } \\
\text { profesar }\end{array}$ \\
\hline Vera Cruz, Bérriz & 1550 & 1741 & $\begin{array}{c}\text { Último beaterio } \\
\text { vizcaíno en abrazar la } \\
\text { clausura }\end{array}$ \\
\hline Ajanguiz & 1548 & 1625 & $\begin{array}{c}\text { Trasladarse a } \\
\text { Rentería-Guernica }\end{array}$ \\
\hline Arrancudiaga & 1548 & - & $\begin{array}{c}\text { Unión con las de La } \\
\text { Naja (no todas) entre } \\
1652-1767\end{array}$ \\
\hline Larrabezúa & 1548 & - & $\begin{array}{c}\text { Teorías de que se } \\
\text { transformó en un } \\
\text { beaterio franciscano }\end{array}$ \\
\hline Ibarra-Orozco & 1573 & 1652 & - \\
\hline Santurce & $\begin{array}{c}\text { Antes de } \\
1578\end{array}$ & Nunca & $\begin{array}{c}\text { Desaparición en el } \\
\text { siglo XIX }\end{array}$ \\
\hline
\end{tabular}

Fuente: MM. Mercedarias Monasterio de San José. Lañomendi, Loiu, Bilbao 2017: $43 .{ }^{30}$

Sabemos que las beatas mercedarias de Vizcaya, al igual que las beatas de otras Órdenes, ${ }^{31}$ recibieron reiteradas visitas de los Superiores de las Órdenes obligándolas a aceptar el enclaustramiento. Concretamente, durante el generalato de Fray Francisco Maldonado se ordenó que las beatas mercedarias lo abrazasen, aunque ninguna comunidad vasca lo hizo. ${ }^{32}$ En $1578,{ }^{33}$ el propio Maldonado realizó una visita y recogió en sus escritos que había diez beaterios mercedarios en todo el País Vasco. ${ }^{34}$ Sin embargo, debido a la pobreza de los mismos, las beatas deberían profesar la clausura y reagruparse en cuatro conventos, algo que, como la tabla 1 refleja, no sucedió.

El beaterio mercedario de Santurce, junto con el agustino de Marquina, fueron los únicos beaterios vizcaínos que sobrevivieron hasta el siglo XIX sin haber profesado la clausura. En el caso de las agustinas de Marquina, sabemos que el beaterio se extinguió el 10 de abril de 1846 con el fallecimiento de Dolores de Aguirre Amalloa, la última beata. ${ }^{35}$ Se suele decir que, desde mediados del siglo XVII, los beaterios y las beatas constituyeron una auténtica rareza ${ }^{36} \mathrm{y}$, sin embargo, estas dos comunidades

30 Las fechas son orientativas ya que es posible ver que los historiadores que han tratado esta cuestión cronológica han solido recoger distintos años, aunque estos son muy cercanos. Como ejemplo de este cambio cronológico leve: Intxaustegi Jauregi 2018a: 1162.

31 Para profundizar sobre la recepción de la clausura en Vizcaya: Intxaustegi Jauregi 2014, 2015 y 2017b.

32 Laka Kortabitarte 2002: 467

33 Boletín de la Orden de la Merced, Año XVII, no 1-2: 12.

34 Nueve estaban en Vizcaya (Arrancudiaga, Bérriz, Bilbao, Deusto, Larrabezúa, Marquina, Múgica-Guernica, Orozco, Santurce) y el restante en Lete-Escoriaza, Guipúzcoa.

35 Labayru 1968: 231.

36 Soriano 2000b: 484 nos muestran que los beaterios no fueron totalmente

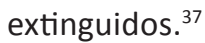

Por lo tanto, ¿cómo es que en Vizcaya hubo beaterios que perduraron tanto en el tiempo? Claramente, estamos ante una cuestión que requiere mayor detenimiento, pero se puede decir que el enfrentamiento que existió contra el obispo, jugó un papel importante en la perduración de estas comunidades. Cabe decir que esta circunstancia también se dio en otros territorios de Castilla, aunque sin llegar a los extremos vizcaínos. ${ }^{38}$ Esa oposición e intransigencia estuvo muy ligada a la supervivencia del patronato laico a manos de los linajes y de ciertas instituciones vizcaínas. Si bien es cierto que el régimen del patronato nobiliario no fue inusual en otras zonas de la Monarquía, ${ }^{39}$ tuvo algunas características que influyeron indudablemente en el devenir de la Iglesia vasca hasta el siglo XIX, especialmente en el Señorío vizcaíno. Durante los siglos medievales, debido a herencias, donaciones, compras, o concesión personal por parte del señor de Vizcaya o de los sucesivos monarcas a cambio de los servicios prestados, los principales linajes solariegos vascos se fueron haciendo con el patronazgo de iglesias y monasterios. ${ }^{40}$ Esos patronos se apropiaron no sólo del derecho de presentación de los clérigos sino también del goce de los diezmos en iglesias y, como para muchos linajes esas prerrogativas constituían más de la mitad de sus ingresos anuales, no se podían permitir el lujo de perderlos en favor de los obispos. ${ }^{41}$ Por lo tanto, esta coyuntura aclara su negativa a aceptar que los prelados ejerciesen autoridad alguna sobre las iglesias ya que ellos las consideraban propias. ${ }^{42}$ Por otra parte, no hay que olvidar que los patronatos también denotaban poder, por lo que cuando los patronos rehusaban a los agentes enviados desde la diócesis, estaban preservando su supremacía y autoridad sobre la población de Vizcaya. ${ }^{43}$ Hay que tener en cuenta que, además de percibir rentas, a través de los patronazgos estas estirpes estructuraban y organizaban sus estrategias económicas y sociales, llegando a realizar un control vecinal, incluso, a nivel psicológico. ${ }^{44}$

Por su parte, la oposición a la autoridad diocesana por parte de los Parientes Mayores y de los cabildos de muchas iglesias se sumó a otros impedimentos como los problemas que representaba gobernar un territorio como el vizcaíno que estaba dividido en dos obispados (Calahorra-La Calzada y Burgos), con una geografía adversa, y una lengua totalmente diferente, coyuntura que complicó e, incluso, imposibilitó muchas visitas pastorales. Además, los Parientes Mayores lograron la institucionalización de su enfrentamiento con la

37 Por su parte, en Europa, donde irónicamente la clausura en términos generales fue abrazada con mayor prontitud que en el País Vasco, también hubo comunidades que sobrevivieron a la cruzada dirigida desde Roma y no sufrieron la clausura. Rapley 1990: 41.

38 Val Valdivieso 1986: 82.

39 Sobre el tema en general, véase Atienza López 2008: 67-82.

40 Es el caso de los Guevara, Lazcano y Balda en Guipúzcoa, y en Vizcaya, los Albiz, Aretaga, Yarza, Ibáñez de Marquina, Marzana, Ibargüen, Zaldívar, Bérriz, Leguizamón, Ayala, Avendaño, Meceta, Villela, Múgica, Anuncibay, Butrón. Dacosta Martínez 1999; Lafarga Lozano 1970.

41 Catalán Martínez 2004: 147-148.

42 Curiel Yarza 2009: 71.

43 Dacosta Martínez 2001: 59-60.

44 Díaz de Durana 1998: 505-506. 
jurisdicción episcopal cuando en el Fuero Viejo de $1452^{45}$ se recogió, específicamente en su capítulo $\mathrm{CCVI},{ }^{46}$ la prohibición de la entrada del obispo en el Señorío. Es decir, lograron que las instituciones vizcaínas les protegiesen en una situación hostil que, hasta entonces, había sido de carácter privado $y$, de ese momento en adelante, se transformó en un enfrentamiento entre dos instituciones: el obispado y el Señorío. ${ }^{47}$ De esta manera, el impedimento a que el obispo pudiera cruzar las fronteras perduró hasta 1539. Después, gradualmente, se realizaron algunas concesiones, pero no fueron muy amplias ya que, por una parte, se temía que el obispo se pudiera entremeter en el problema de las luchas de los bandos. Además, también les movían razones económicas al querer dominar las iglesias vizcaínas y cobrar sus diezmos y primicias, mientras clérigos y fieles se veían libres del pago de la limosna, el subsidio, el sello y la visita canónica al obispo. ${ }^{48}$

Ante esta coyuntura, es comprensible la subsistencia de las beatas hasta el siglo XVII, ya que hasta la centuria previa las beatas habían dependido de los ayuntamientos o de las iglesias locales, muchos de los cuales eran controlados por Ios Parientes Mayores. Pero, como durante el siglo XVI varias comunidades empezaron a abrazar una orden religiosa, la influencia de la Iglesia sobre las beatas comenzó a ser mayor. Asimismo, hay que decir que para la década de 1560 el vínculo entre las instituciones vizcaínas y el obispado fue más continuo y, precisamente, fue a partir de ese momento cuando se comenzó a solicitar la clausura de los beaterios. Es imprescindible recordar que en el Capítulo V de la Sesión XXV del Concilio de Trento se decidió que los obispos eran los encargados de implantarla en las comunidades en las que todavía no existía. Por lo tanto, el hecho de que el obispo estuviese vetado en el territorio vizcaíno se perfila como una razón importante a la hora de explicar su lento establecimiento en la mayoría de los beaterios vizcaínos. Sin embargo, hay que tener en cuenta que en los conventos de religiosas dominicas de Lequeitio y Bilbao se abrazó la clausura antes del Concilio de Trento, concretamente en el siglo XIV y en la década de 1520. Es decir, las cuestiones relativas al patronato laico y a la delicada situación del obispo en Vizcaya dilataron su establecimiento, pero no han de ser vistos como motivos absolutos porque el enclaustramiento ya era conocido en el Señorío.

Por su parte, hay que decir que en el año 1595 el obispo don Pedro de Manso realizó una visita al Señorío, pero fue la visita que en 1615 hizo el obispo Pedro González del Castillo la que marcó la diferencia. El obispo denunció el desastroso estado de las iglesias, del clero y del culto vizcaínos como consecuencia de las acciones de sus patronos, por lo que el monarca ordenó al corregidor una investigación al respecto. Así, poco tiempo después, los patronos laicos se vieron obligados a abonar no sólo las obras necesarias en los templos, sino también una cuota fija en metálico o en su defecto una parte de los diezmos para la fábrica.

45 El Fuero Viejo, escrito en 1452, recogía por escrito el ordenamiento institucional, civil, penal y procesal, que procedía de la costumbre, del Señorío de Vizcaya.

46 Celaya Ibarra 2005: 22.

47 Curiel Yarza 2009: 234

48 Gastañazpi 1994: 23.
Estos hechos debilitaron la economía de los patronos, ${ }^{49}$ y también disminuyó la autonomía de los patronos en el nombramiento de los clérigos, que constituía la otra base de poder del patronato laico. Asimismo, durante esas fechas los beaterios también fueron asediados para que abrazasen la clausura $y$, en consecuencia, se transformasen en conventos. Claramente, las fechas entre el enclaustramiento de las beatas y el período de mayor injerencia de la Iglesia y el poder episcopal en Vizcaya coinciden. Si bien en este artículo se trata la familia mercedaria, las fechas en las que los beaterios de franciscanas se encerraron (Tabla 2) refleja claramente como los cambios en las relaciones con el obispo influyeron en las comunidades religiosas vizcaínas.

TABLA 2

Clausura en los beaterios de franciscanas en Vizcaya

\begin{tabular}{|c|c|}
\hline BEATERIO & CLAUSURA \\
\hline Beaterio de Orduña & 1585 \\
\hline Beaterio de Durango & 1599 \\
\hline Beaterio de Santa Bárbara de Abando & 1603 \\
\hline Beaterio de Santa Cruz de Bilbao & 1614 \\
\hline Beaterio de Portugalete & 1614 \\
\hline Beaterio Concepcionistas de Abando & 1615 \\
\hline Beaterio de Gordejuela & 1618 \\
\hline Beaterio de Guernica & 1618 \\
\hline Beaterio de Villaro & 1627 \\
\hline Convento Santa Clara de Balmaseda & $1665-66 *$ \\
\hline
\end{tabular}

Fuente: Elaboración propia a partir de datos en obras diversas de Rodríguez Condado 1994, 1995, 1997, 1998 y 2000; Uribe 1998. *Fundado entonces como convento

Como hemos visto en la tabla 1 , los beaterios de mercedarias también abrazaron la clausura en el siglo XVII, aunque lo hicieron bastante después que las franciscanas $y$, en algún caso, en el siglo XVIII, como fue el caso de las de Bérriz.

En el resto de la península, los beaterios también tuvieron un peso importante, y muchos conventos tienen su origen, precisamente, en beaterios, ${ }^{50}$ como sucedió en las localidades de Zamora, ${ }^{51}$ Sanlúcar, ${ }^{52}$ Carmona, ${ }^{53}$ León, ${ }^{54}$ o Jaén. ${ }^{55}$ Por su parte, mientras en el continente europeo los dirigentes eclesiásticos buscaron el fin de las mujeres semireligiosas, en las colonias americanas los beaterios fueron bienvenidos. Así, conforme progresaba la colonización, se dio una propagación de la fe cristiana y, en consecuencia, se fundaron conventos para acoger a mujeres. Sin embargo, también hubo fundaciones beateriales, incluso, en el siglo XVIII cuando, en torno al año 1726, se llevó a cabo la fundación del beaterio de Nuestra Señora de la Merced de Quito. ${ }^{56}$

\footnotetext{
49 Larrea Beobide 2001: 190.

50 Atienza López 2008: 96.

51 Álvarez Rodríguez 2015; Frohnapfel 2013.

52 Rodríguez Duarte 2017.

53 Mira Caballos y Villa Nogales 1999.

54 Pérez Álvarez 2014.

55 Serrano Estrella 2007.

56 Viforcas Marinas 1993: 358.
} 
El porqué de la existencia de beaterios en el continente americano se debe a la coyuntura socio-étnica que se vivía, ya que las comunidades religiosas a cargo de los peninsulares no permitían la entrada a las indígenas. Éstas solamente tenían acceso si desempeñaban labores de criadas; por ello, se crearon beaterios exclusivos para las nativas. ${ }^{57}$

\section{El BEATERIO DE SANTURCE: FUNDACIÓN, DESARROLLO Y DISOLUCIÓN}

La documentación revela que en Santurce existieron dos beaterios. Ignoramos su fecha de fundación, pero María José Arana recoge que antes del siglo XVI ya existían,, ${ }^{58}$ y acabaron siendo habitados por beatas isabelinas $y$ mercedarias. El de las isabelinas desapareció cuando sus beatas se trasladaron al beaterio de Portugalete, que se transformó en el convento de Santa Clara. ${ }^{59}$ Aunque desconocemos la fecha concreta de tal partida, sabemos que para 1655 el beaterio no existía ya que en ese año se celebró un pleito entre los conventos de San Francisco y San Mamés de Bilbao, el de Santa Clara de Castro Urdiales y el de Santa Clara de Portugalete por las tierras y los bienes que pertenecieron al beaterio de Santurce. ${ }^{60}$ Por su parte, el beaterio mercedario, que sobrevivió hasta el siglo XIX, era muy apreciado por la población, hecho que se refleja en la descripción que realizó José Ramón Iturriza cuando recogió que en el año 1783, Santurce tenía unas 120 casas con 500 habitantes, y destacaba la existencia del beaterio. ${ }^{61}$

¿Qué sabemos sobre la vida de esta comunidad mercedaria? Hay que decir que la documentación conservada no es mucha y que, además, se encuentra bastante dispersa en distintos archivos como son el Archivo del Monasterio de las Madres Mercedarias de Loiu, el Archivo Histórico Provincial de Bizkaia, el Archivo Foral de Bizkaia, y el Archivo Histórico Eclesiástico de Bizkaia. No obstante, tras una búsqueda exhaustiva pertinente, nos ha sido posible vislumbrar información al respecto.

En primer lugar, podemos decir que el idioma utilizado por las beatas era el vasco ya que cuando el Padre Maldonado visitó Santurce, necesitó de un intérprete, ${ }^{62}$ algo que también le sucedió en los beaterios de Arrancudiaga y de Marquina. ${ }^{63}$ Hay que decir que la cuestión lingüística resulta esencial en cualquier estudio vasco durante la Edad Moderna ya que es un aspecto que sorprendió a todos los viajeros que visitaron el territorio. ${ }^{64}$ Resulta esencial recordar que nos encontramos ante una población que era prácticamente monolingüe vasca. Así, para comienzos del siglo XVII, se estima que en Vizcaya había unos 74.000 habitantes, de los cuales 64.380 eran vascoparlantes monolingües, lo que representa el $87 \%$ de la sociedad vizcaína. Por su parte, se cree que, para el año 1800, había 112.371 habitantes, de los

\footnotetext{
57 Espinosa Soriano y Baltasar Olmeda 2010: 135.

58 Arana 2002: 848.

59 Archivo del Convento de Santa Clara de Portugalete [ACSCP], Historia del Convento.

60 Archivo Histórico Provincial de Bizkaia [AHPB], Francisco Maribi de Allende, 5110.

61 Iturriza Zabala 2000: 320.

62 Laka Kortabitarte 2002: 468.

63 Boletín de la Orden de la Merced, 1930. Año XVII, no1-2: 12.

64 Reguera y Angulo Morales 2004: 15.
}

cuales 93.371 eran vascoparlantes monolingües, es decir, el $83,1 \%$ de la población del Señorío. ${ }^{65}$ Cabe añadir que esta cifra aumentaba en el caso de las mujeres porque éstas no tenían las posibilidades que sí contaba el género masculino de ir a colegios donde estudiaban la lengua castellana. ${ }^{66}$

Por otra parte, conocer la identidad de las beatas que formaron esta comunidad beaterial no es una tarea sencilla ya que no existen listados al respecto. No obstante, ha sido posible conocer la identidad de alguna de ellas, especialmente durante el siglo XVIII, como puede verse en la tabla 3 (Anexo). Sí podemos decir que era una comunidad muy pequeña y que, teniendo en cuenta la documentación, seguramente no superaba los cinco miembros. Cuando se realizaban escrituras públicas, lo habitual era que el documento se iniciase con una referencia a las beatas presentes y éstas nunca superaban tal cifra. Además, sabemos que existió una gran variedad respecto a las beatas, y no todas profesaron siendo unas adolescentes, que era la tónica habitual en la época. Gracias a la estadística, sabemos que lo normal fue que una mujer profesase para monja cuando contaba entre dieciséis y veinte años. ${ }^{67}$ En los escasos documentos donde se recoge la profesión de beatas, no aparece recogida su edad, por lo que no nos es posible determinar si sucedía lo mismo que en los conventos, pero como las similitudes entre ambos espacios religiosos fueron habituales, es una posibilidad que no hay que descartar. Por otra parte, sabemos que Francisca del Balle, que llegó a ser comendadora de la comunidad, profesó una vez se había quedado viuda del capitán Juan de Zuazo, vecino de Santurce. ${ }^{68}$ La edad media de acceso al primer matrimonio de las mujeres era de 26 años de edad, ${ }^{69}$ por lo que podemos decir que profesó ya siendo una mujer adulta. Cabe decir que no era algo inusual que mujeres que habían estado casadas acabasen habitando en una comunidad de religiosas, ${ }^{70}$ tanto en conventos como, en este caso, en beaterios.

Respecto a su procedencia geográfica, es posible ver que estamos tratando con un ámbito geográfico muy concreto. Las beatas que profesaron eran vecinas de Santurce o de localidades cercanas, como Portugalete o Ciérbana, circunstancia que, una vez más, se repitió con la mayoría de las monjas quienes profesaban en conventos de su misma localidad o, a lo sumo, de la diócesis. ${ }^{71}$ Asimismo, esta dinámica también se repitió en conventos europeos, lo que facilitó que en ocasiones las mujeres ya se conocieran de su vida laica. ${ }^{72}$ Además, como podremos ver en el apartado de los censos, quienes los fundaban también eran vecinos de Santurce o de alrededores, lo que nos permite constatar que se trataba de una comunidad con un ámbito de influencia pequeño, coyuntura que, sin embargo, no impidió que se repitiesen las mismas pautas que en otras zonas vizcaínas e, incluso, europeas.

Por otra parte, es necesario preguntarse cómo funcionaba la comunidad. De la poca documentación que ha sobre-

\footnotetext{
65 Madariaga Orbea 2014: 732-734.

66 López Atxurra 2000: 437.

67 Pi Corrales 2010: 17.

68 AHPB, Juan Ángel de Zuazo 7067/5.

69 Ortega Berruguete 1990: 199.

70 Para más información sobre mujeres casadas y viudas en conventos y beaterios: Rey Castelao 2011.

71 Barrio Gozalo 2002: 73.

72 Strocchia 2009: 48
} 
vivido, nos ha llegado una copia de las ordenanzas del año $1688^{73}$ por las que se regía la comunidad, y éstas nos aportan una rica información. Las ordenanzas fueron aprobadas por el arzobispo de Burgos, ya que no hay que olvidar que la parte oriental del Señorío de Vizcaya perteneció al obispado de Burgos y desde el año 1754 a la diócesis de Santander, que se había desgajado de la de Burgos, mientras que una gran parte del territorio vizcaíno formaba parte de la diócesis de Calahorra-La Calzada.

Las ordenanzas comienzan diciendo que la comunidad cumplía con los votos de pobreza, obediencia y castidad, pero no el de la clausura. Claramente, la ofensiva enclaustradora postridentina a la que ya nos hemos referido anteriormente no tuvo el éxito deseado por el Vaticano, y siguieron existiendo comunidades religiosas femeninas donde la clausura no rigió. Asimismo, al no vivir en clausura, no existía un locutorio, que es el espacio reservado para las visitas del exterior, por lo que mujeres no beatas podían entrar a la comunidad e, incluso, subir a las celdas para hablar con las beatas. No obstante, los hombres sí tenían restricciones y no podían pasar de la capilla; es más, las beatas tenían prohibido hablar con hombres fuera del beaterio y solamente podían hacerlo si se trataba de un pariente.

Además de las referencias del locutorio y de la capilla, también se nos ofrece una descripción del edificio. De esta manera, sabemos que los dormitorios eran unas celdas muy austeras y sin apenas decoración. Las beatas tenían prohibido tener escritorios, pero sí podían poseer algún cofre o algún arca de nogal. Por otra parte, tampoco había puertas porque se utilizaban cortinas de tela muy modesta. Las camas eran de medios mástiles, de poco precio, y se utilizaban telas blancas, dos almohadas, y dos mantas. Cuando una comunidad abrazaba la clausura se debía de llevar a cabo una serie de obras para acondicionar el espacio a los requisitos de la clausura, como era la construcción de muros o el cierre de ventanas. Precisamente, San Carlos de Borromeo publicó en el año 1577 las instrucciones Fabricae et Supellectilis Ecclesiasticae y en 1599 el Acta Ecclesiae Mediolanensis, obras rápidamente distribuidas por todo el mundo católico en las que se recogían cuáles eran las reformas necesarias y cómo debían llevarse a cabo. ${ }^{74}$ Es decir, que como este beaterio no abrazó la clausura y, por lo tanto, no llevó a cabo esas reformas, es bastante posible que el beaterio hubiera mantenido la estructura y características medievales, aunque, obviamente, con necesarias reformas durante la Edad Moderna.

Las beatas debían vestir de blanco, siguiendo las reglas de la vestimenta que regían en la Orden de la Merced..$^{75}$ Además, en el vestido interior no podían llevar ninguna ornamentación ni tener joyas, austeridad compartida con las monjas. ${ }^{76}$ Finalmente, las beatas debían de cuidar la modestia y la compostura, y hablar sin levantar la voz, actitudes que nos demuestran que la Iglesia buscaba un modelo de la buena monja que incluía las cualidades deseables en toda mujer como eran la obediencia, la

73 Archivo Histórico Eclesiástico de Bizkaia [AHEB] Ordenanzas del Beaterio de la Merced de Santurce, 3105/010-00 / Madres Mercedarias Monasterio de San José 2017: 47-51.

74 Evangelisti 2007: 47.

75 Biblioteca Mercedaria 1977: 29.

76 Pi Corrales 2010: 20. modestia, la discreción, la devoción y el silencio, todo ello en grado sumo, ${ }^{77}$ ya que al igual que el honor de las familias se hacía descansar sobre la integridad y la honra de sus mujeres, debía entenderse que la reputación de la Iglesia dependía de la clausura de las religiosas porque eran sus mujeres consagradas a la religión. ${ }^{78}$

El noviciado duraba un año y se abonaban tres ducados mensuales por los alimentos, es decir, 36 ducados anuales. Por su parte, el día de la profesión se debía pagar la dote, que ascendía a 250 ducados, en censos. En este punto, es posible ver, una vez más, similitudes con las monjas. Hay que decir que dentro del mundo monjil hay que diferenciar dos tipos de monjas: las de velo negro y las de blanco, también conocidas como monjas de coro y legas respectivamente. Las primeras pagaban una dote que a finales del siglo XVII se fijó en los 1.000 ducados y eran quiénes ocupaban los cargos de gobernabilidad del convento, mientras que las segundas realizaban un pago menor, normalmente un tercio, lo que conllevaba el no poder acceder a cargos superiores y encargarse solamente de las tareas domésticas del convento. ${ }^{79}$ Por ejemplo, en el año 1662 María de Mantada profesó como monja lega en el convento de Santa Clara de Portugalete y abonó 150 ducados de vellón en un censo por la dote y 10 ducados en alimentos, ${ }^{80}$ mientras que en el año 1781 profesó María Antonia de Santa Rosa y Unzaga abonando 300 ducados de dote y 30 ducados por los alimentos. ${ }^{81}$ Vemos que las cifras a abonar tanto por las beatas como por las monjas legas fueron similares, y también muy bajas en comparación con las de las monjas de coro, ya que éstas solían abonar 1.000 ducados por la dote y 50 ducados por los alimentos del noviciado, que es lo que pagó Juliana de Sabando y Balderico cuando profesó en el año 1775 en el mencionado convento portugalujo. ${ }^{82}$ No hay que olvidar que hasta las desamortizaciones del siglo XIX, las religiosas constituían un colectivo improductivo, por lo que en el Concilio de Trento se estableció la obligatoriedad dotal como garantía para el sustento monjil, ${ }^{83}$ hecho que explica la presencia de las dotes en el mundo religioso femenino.

Por su parte, las beatas tenían un horario distinto dependiendo de si era verano o invierno. De esta manera, en verano se solía tocar la campana a las 5:30 para que a las 6:00 todas estuviesen levantadas y vestidas, mientras que en invierno todo ello se realizaba una hora más tarde. El resto del día estaba dividido en rezos, labores y misa.

En las ordenanzas también se recoge cómo era elegida la madre comendadora, que era la beata que dirigía la comunidad. Ella era elegida por todas, con excepción de las novicias, en unas elecciones donde el voto era secreto. Sin embargo, respecto a los demás cargos, las novicias sí podían participar. Por su parte, en los conventos las novicias tampoco podían participar en las elecciones de las abadesas o prioras, aunque tampoco elegían los otros cargos. ${ }^{84}$ Finalmente, en las ordenanzas se recoge que se debía realizar un inventario de

\footnotetext{
77 Vigil 1998: 216.

78 Atienza López 2014: 810

79 Roest 2013: 244.

80 AHPB, Simón Pucheta 5580/2.

81 AHPB, Antonio Agustín Quintana 7060/2.

82 AHPB, Antonio Agustín Quintana 5925/1.

83 Rey Castelao 2009: 60.

84 Prada Camín 2013: 144.
} 
todos los bienes y recogerlos en un libro. El dinero se guardaba en un arcón con dos llaves: una la guardaba la madre comendadora y la otra una beata elegida por todas. Las beatas podían sacar su dinero cuando lo necesitaban, aunque para ello era necesaria la aprobación de la madre comendadora.

Respecto a la economía conventual, ¿de qué medios se valieron para el día a día? Ciertamente, en el imaginario actual que tenemos sobre las economías de comunidades religiosas femeninas predomina la imagen de los dulces, pero en las comunidades vizcaínas, al igual que sucedía en otros conventos del mundo católico, ${ }^{85}$ los dulces, los bizcochos o el chocolate eran productos que se utilizaban como regalos y no tanto como ganancia económica. Por lo tanto, teniendo en cuenta que estamos tratando sobre una comunidad religiosa, las beatas también siguieron las pautas dadas en otras instituciones eclesiásticas. Como la Iglesia siempre ha sido la gran institución censualista por excelencia, ${ }^{86}$ no ha de sorprender que en los beaterios los censos también tuvieran un peso significativo. Los censos tuvieron una rentabilidad muy alta en el siglo XVI, del 7 al $10 \%$ de renta anual, situación que empezó a cambiar a comienzos del siglo XVII cuando se realizó una rebaja en el porcentaje anual hasta situarlo en el $5 \%$. En el siglo XVIII volvieron a ser reducidos, esta vez hasta el $3 \%$ pero, sin embargo, la Iglesia continuó apoyando esta figura del derecho real. ${ }^{87}$ De esta manera, la nobleza, los concejos o los campesinos fundaban censos para hacer frente a sus necesidades, mientras que las instituciones eclesiásticas llegaron a convertirse en los principales prestamistas y, por tanto, en los principales beneficiarios de esta forma de detracción de excedente. ${ }^{88}$

El beaterio de Santurce fue dueño de unos cuantos censos, cuyos réditos ayudaron a la comunidad. Así, el 1 de noviembre de 1645 Marcos Ortiz de Larrea, vecino del San Salvador del Valle, fundó un censo de 400 reales, que tenía 20 reales de réditos, a favor de María Cruz de Pagoa y Tomás Fortuso, quienes en abril de 1649 cedieron el censo al beaterio, cuando la comendadora de la comunidad era Teresa de Jesús. ${ }^{89}$ Por su parte, en el año 1674 el beaterio redimió un censo de 100 ducados de vellón que pertenecía a Pedro de la Ormaza el Menor, vecino de Santurce y heredero de Juan de Pucheta, quién, por su parte, lo había fundado el 15 febrero de $1619 .{ }^{90}$ Asimismo, también hubo beatas que a título particular fueron beneficiadas de los censos. Por ejemplo, el 1 noviembre 1650 Francisco de Murrieta, vecino de Santurce, vendió un censo de 265 reales y con una renta anual de 460 maravedís, a la beata María de Egurgui Aguirre, ${ }^{91}$ o en el año 1686 la beata Catalina del Valle vendió un censo de 70 ducados, que tenía una renta 2 reales, a María Iñiguez de Oyanza, viuda vecina de Santurce. ${ }^{92}$

Los motivos por los que las beatas fueron dueñas de censos se fundamentaron en distintas razones. Como ya se ha indicado, cuando una mujer ingresaba como beata debía aportar una dote, hecho que explica que la comunidad pose-

\footnotetext{
85 Arias González 2007: 101.

86 Domínguez Ortiz 2000: 799.

87 Barrio Gozalo 2002: 82.

88 Atienza López 1991: 499.

89 AHPB, Simón Pucheta 4868.

90 AHPB, Francisco de Oyanzas y Nocedal 5916/5.

1 AHPB, Diego Zubiete 4797/4.

2 AHPB, Francisco de Oyanzas y Nocedal 7071/1.
}

yese censos abonados como pago por la dote. De esta manera, se pueden mencionar las entradas en los beaterios, aportando censos con ellas, de las beatas María de Ygareda con un censo de 250 ducados en el año 1685, ${ }^{93}$ Josefa Umaran en el año 1711 aportando 350 ducados, ${ }^{94}$ o en 1713 Francisca del Balle con un censo de 300 ducados que tenía una renta anual de 9 ducados. ${ }^{95}$ Por su parte, el 11 de mayo de 1718 , el licenciado Bernarve Nozedal, cura y beneficiado del Concejo, entregó a las beatas un censo de 300 ducados como dote de su sobrina Ana María de Santa Rosa y Nozedal, ${ }^{96}$ y la misma cantidad fue la que aportó en el año 1728 María Trinidad de Pucheta, al llevar un censo de 125 ducados y otro de 175 ducados. ${ }^{97}$ Finalmente, en 1786, Francisca del Corazón de Jesús García profesó y entregó 5.500 reales en moneda de oro y de plata de dote en un censo, como se pactó cuando inició el noviciado. ${ }^{98}$ Podemos ver que las cantidades no eran fijas y que fueron variando, si bien es cierto que con una tendencia ascendente según iba pasando el tiempo.

En otras ocasiones, que la comunidad fuese dueña de censos se debió a una cesión recibida como pago de una deuda, que es lo que ocurrió en el año 1705, cuando el matrimonio Pedro Quartier y María de Arregui, vecinos de Sestao, cedieron un censo de 100 ducados de principal y 5 ducados de renta anual, que había sido fundado en 1655 , a favor de las beatas. ${ }^{99}$

Por su parte, ya hemos visto como en Arrancudiaga hubo un beaterio mercedario que acabó disuelto. Como se ha recogido en la tabla 1 , la mayoría de las beatas de este beaterio fueron al de La Naja de Bilbao pero, al menos, una beata de esta comunidad de Arrancudiaga fue al de Santurce, y con ella se llevó un censo y dinero en efectivo del beaterio extinguido. Hay que decir que no se sabe la fecha exacta de la disolución de la comunidad de Arrancudiaga, pero sabemos que en el año 1644 el beaterio estaba vendiendo censos y propiedades por las estrecheces por las que estaba pasando, ${ }^{100}$ mientras que el 28 de febrero de 1688 se indica que la beata María Asunción de Mendieta Echavarría, que había profesado en Arrancudiaga y era natural del valle de Orozco, había llegado al beaterio de Santurce hacía unos veintiocho años, es decir, que para las décadas de 16501660 el beaterio desapareció o, al menos, esta beata fue al de Santurce. Juan Laka indica que entre 1652 y 1676 las pocas beatas del beaterio se trasladaron al de Bilbao, ${ }^{101}$ pero gracias a la documentación del Archivo Histórico Provincial de Bizkaia sabemos que, al menos, una fue al de Santurce.

Ese censo en cuestión tenía un valor de 200 ducados y había sido fundado por el licenciado Echavarría, cura y beneficiado de las iglesias de Güeñes, como principal, y San Martín de Zollo y el matrimonio Diego de Escarzaga y María López de Echavarría como fiadores, todos ellos vecinos de Güeñes. Antes de que el censo pasase a manos del beaterio de Santurce, sus fundadores redimieron 100 ducados, por lo que en el año

\footnotetext{
93 AHPB, Francisco de Oyanzas y Nocedal 7071/2.

94 AHPB, Francisco Villar y Cotillo 7064/3.

95 AHPB, Francisco Villar y Cotillo 5926/2.

96 AHPB, Pedro Oyanzas y Zuazo 7074/4.

97 AHPB, Pedro Oyanzas y Zuazo 7074/4.

98 AHPB, Francisco Javier de Ibarra 7078/4.

99 AHPB, Francisco Villar y Cotillo 5926/1.

100 AHPB, Martín de Baquiola 3125.

101 Laka Kortabitarte 2002: 467.
} 
1688 las beatas de Santurce, cuando vendieron el censo a Pedro de Zuazo, el censo tenía un valor de 100 ducados. ${ }^{102}$ Además, la beata María Asunción de Mendieta Echavarría también llevó consigo 200 ducados, que fueron utilizados cuando el 17 diciembre 1665 el matrimonio Marcos de las Tres y Catalina de la Sierra como principales y su padre Domingo de la Sierra como fiador, fundaron un censo de 200 ducados vellón y una renta de 10 ducados a favor de las beatas. ${ }^{103}$

Por otra parte, los réditos anuales que se recibían por los censos no siempre se abonaron, por lo que fue habitual que se iniciasen pleitos al respecto. Un ejemplo de esto lo encontramos en el año 1667, cuando las beatas iniciaron un pleito ya que se les debían todos los réditos, en total 327 reales y medios, de un censo de 50 ducados de principal y 2' 5 de renta anual fundado en 1623 por Sancho de Oyanzas. ${ }^{104}$ En ese mismo año también comenzaron un pleito ya que se les debía 45 ducados por los réditos de un censo 100 ducados de vellón que el beaterio heredó al recibir los bienes de María de Baracaldo, viuda de Juan de Riva. ${ }^{105}$

Asimismo, sabemos que en otras ocasiones las propias beatas vendieron los censos, especialmente, a partir del siglo XVIII ya que la ganancia no era tan elevada. Así, el 23 de mayo de 1712, las beatas vendieron un censo de 35 ducados y 1.402 maravedís de renta anual que había sido fundado en el año 1613 por el matrimonio formado por Pedro de Nocedal y María de Samaduo, vecinos de Santurce, a favor del almirante Martín de Ballecilla y Catalina del Casal, matrimonio vecino de Portugalete. El 18 agosto 1654, el heredero, también llamado Martín de Ballecilla, vecino de Portugalete y Sestao y caballero de la Orden de Santiago, vendió ese censo, junto a otros, al beaterio. En el año 1712, Juana de Puncheta, viuda de Domingo de Ygareda, abonaba los réditos, y las beatas se lo acabaron vendiendo a su hijo, Fernando Ygareda. ${ }^{106}$ Finalmente, en el año 1787, las beatas vendieron un censo de 100 ducados a Pedro de Loredo, presbítero, cura y beneficiado de la parroquia de Santurce. Este censo lo había fundado Ángela de Ballebian, viuda vecina de Santurce, el 27 mayo 1731 ante el escribano Pedro de Oyanzas y Zuazo y a favor del beaterio. ${ }^{107} \mathrm{Sin}$ embargo, cabe decir que, si bien en el siglo XVIII las beatas se dedicaron a vender distintos censos que poseían, eso no les impidió adquirir otros, como sucedió el 13 de enero de 1788, cuando María de Zuazo, esposa de Ramón de Sopardo, loco y ausente, vendió un censo de 27 ducados a la comunidad. ${ }^{108}$

Claramente, podemos ver que se dio una presencia importante de las rentas de capital, coyuntura compartida con los conventos femeninos. No obstante, los problemas en el cobro de las rentas, la caída de los intereses y las dificultades crecientes en su gestión, indujeron a una reorientación de las inversiones hacia bienes inmuebles por parte de las comunidades femeninas durante el siglo XVIII. ${ }^{109}$ Este proceso, en el que el entorno urbano que rodeaba a los conventos se convirtió en el objetivo de sus inversiones,

\footnotetext{
102 AHPB, Francisco de Oyanzas y Nocedal 7071/6.

103 AHPB, Simón Pucheta 7094/1.

104 AHPB, Simón Pucheta 7287/1.

105 AHPB, Simón Pucheta 7287/2.

106 AHPB, Pedro Oyanzas y Zuazo 7073/7.

107 AHPB, Francisco Javier Ibarra 7078/5.

108 AHPB, Francisco Javier Ibarra 7079/1.

109 Atienza López 2008: 320.
}

comenzó en la década de 1680, ${ }^{110}$ por lo que de un siglo XVII predominantemente censal pasamos a un siglo XVIII donde el peso específico de los arrendamientos sobrepasó a los ingresos por acciones de créditos. ${ }^{111}$

Hasta el siglo XIX, Santurce era un área totalmente rural, por lo que la adquisición de propiedades y su arrendamiento no fue una práctica tan acentuada como sí lo fue en conventos vizcaínos, especialmente el de Santa Cruz de Bilbao, donde en el siglo XVIII los censos representaban el $13,59 \%$ de los ingresos, mientras que las rentas por los arrendamientos de casas el 53,18\%. ${ }^{112}$ No obstante, eso no significa que el beaterio no fuese dueño de propiedades, ya que lo fue pero en unos porcentajes muy discretos. Al igual que sucedió en conventos alejados de Bilbao, la práctica más habitual fue el arrendamiento de huertas o heredades, como hicieron las clarisas de Durango en 1668 cuando arrendaron unas huertas por 24 reales, ${ }^{113}$ o las de Guernica con nueve peonadas de heredades a la viuda Margarira Ycoaga por espacio de cinco años y con una renta anual de 56 ducados. ${ }^{114}$ De esta manera las beatas de Santurce tuvieron tres propiedades de viñas: una en el puerto de los Haranjos, que lindaba por el sudeste con la viña de José de la Ormaza, otra junto a la viña de Pedro de Allende, y la última al lado de la de Pedro de Elorriaga. El valor total de las tres viñas era de 150 ducados de vellón. ${ }^{115}$ Algunas propiedades también las arrendaban, y así el 7 noviembre 1751 recibieron 180 reales de vellón por el arrendamiento de unos terrenos a Pablo de la Peña, vecino de Santurce. ${ }^{116}$ Por su parte, otras propiedades fueron vendidas, como sucedió en el año 1714 con unas heredades para sembrar, concretamente 784 brazas, que tenían en el sitio de Villar Galinda en Santurce, por 1.200 reales de vellón al matrimonio formado por Juan Alonso y Bernarda de Nocedal, ${ }^{117}$ mientras que el 30 de octubre de 1744 el matrimonio José de Echavarría y María de Larrazábal, vecinos de Santurce, compraron a las beatas una heredad de tierra para sembrar, llamada Cardosa, de 820 estados que estaba en el barrio de Villar, y su huerto de 117 estados, todo ello por 100 ducados de vellón. ${ }^{118}$

Otra fuente de ingresos importante fueron las herencias. Hay que decir que cuando profesaban en el beaterio, al igual que hacían las monjas, las beatas debían renunciar a sus legítimas paterna y materna pero no a otros derechos sucesorios, por lo que era habitual que recibieran algún tipo de herencia. Por ejemplo, cuando el 1 de agosto de 1728 profesó María Trinidad de Pucheta tuvo que renunciar a las legítimas paterna y materna a favor de sus hermanas Josefa y Ermenegilda Pucheta. ${ }^{119}$ Pero, como hemos indiciado, esas renuncias no afectaban a la herencia, y así el 2 de abril de 1660 la beata María de San Juan de Achuriaga recibió 50 ducados del testa-

\footnotetext{
110 Soriano 2000a: 17.

111 Negredo del Cerro 2005: 31

112 Catalán Martínez 2000: 157.

113 Archivo del Convento de San Antonio de Durango [ACSAD], Documentos antiguos.

114 Archivo del Convento de Santa Clara de Guernica [ACSCG], Asuntos de Forua.

115 AHPB, Manuel Villar 7066/2.

116 AHPB, Manuel Villar 4796.

117 AHPB, Pedro Oyanzas y Zuazo 7073/9.

118 AHPB, Matías de Villar 7054.

119 AHPB, Pedro Oyanzas y Zuazo 7074/4.
} 
mento de su hermano Juan Martínez de Achuriaga. ${ }^{120}$

Finalmente, cabe centrarse en el fin de esta comunidad, que tuvo lugar en el siglo XIX. En el año 1836, un Oficio remitido por la Comandancia General el 11 de mayo recogía otro de la Junta Diocesana de la Provincia de Santander relativo al cumplimiento de dos reales órdenes por las que se ordenaba la supresión de algunos conventos de regulares, así como del beaterio de Santurce. Ese mismo año, la comunidad desapareció, pero el edificio físico sobrevivió hasta el año 1851, cuando se realizó un concurso público para la ejecución de las obras de modificación de la distribución del beaterio para habilitar una sala para celebrar ayuntamientos, y tener un archivo, una cárcel y una escuela con la casa del maestro. ${ }^{121}$

Cabría preguntarse los motivos que ocasionaron que este beaterio sobreviviese hasta el siglo XIX sin haber profesado la clausura. El hecho de que el obispo de Calahorra-La Calzada tuviese prohibida la entrada en el Señorío de Vizcaya explica por qué las beatas tardaron tanto en vivir enclaustradas, pero hay que tener en cuenta dos aspectos. El primero sería que, aunque con retraso, los beaterios vizcaínos, con sólo dos excepciones como ya hemos dicho, acabaron abrazando la clausura. En segundo lugar, no hay que olvidar que la localidad de Santurce pertenecía a la diócesis de Burgos y, posteriormente, a la de Santander, por lo que lo relativo al obispo de Calahorra-La Calzada no influyó en exceso en Santurce. Por lo tanto, ¿por qué sobrevivió este beaterio y no el resto? Hemos visto que las ordenanzas que regían en el beaterio habían sido aprobadas por el obispo de Burgos, lo que refleja que el beaterio existía con el consentimiento diocesano. Otro motivo de peso pudo ser su localización geográfica. Santurce está en la zona de la Margen Izquierda de Vizcaya y en esta zona sólo había otro convento más, el de Santa Clara de Portugalete. Es más, en la zona vecina de las Encartaciones los dos conventos femeninos que existieron también fueron de la familia franciscana, concretamente el de Santa Isabel de Gordejuela y el de Santa Clara de Balmaseda. Por lo tanto, cabe pensar que los superiores de la Merced quisieron conservar una comunidad de su familia en una zona donde la presencia franciscana era casi omnipresente. Además, de los nueve beaterios mercedarios vizcaínos que existieron a comienzos del siglo XVI, la cifra descendió, lo que también puede explicar que la familia mercedaria quisiera que su presencia en Vizcaya no mermase. Finalmente, hemos visto como las dotes a abonar al entrar en un beaterio eran de menor cantidad, lo que facilitaba la entrada en el mundo religioso de mujeres de familias con menos medios. La existencia de comunidades religiosas que acogiesen a mujeres era una circunstancia del agrado de la sociedad de la época, lo que puede también explicar que se permitiese la existencia de este beaterio. Por lo tanto, es imposible especificar qué determinó que esta comunidad perdurase hasta el siglo XIX, pero es un hecho que así lo hizo, algo que podríamos considerar casi un hito teniendo en cuenta las políticas enclaustradoras que se llevaron a cabo desde Roma. Por ello, era necesario rescatar del olvido esta comunidad y dar a conocer su historia.

\footnotetext{
120 AHPB, Simón Pucheta 5579/2.

121 Archivo Foral de Bizkaia [AFB], Santurce 0024/001.
}

ANEXOS

TABLA 3

La comunidad

\begin{tabular}{|c|c|c|}
\hline Año & Identidad & Cargo \\
\hline 1623 & María del Río & Comendadora \\
\hline 1649 & María de la Visitación & Comendadora \\
\hline 1650 & María de Egurgui & Beata \\
\hline 1660 & $\begin{array}{c}\text { María de San Juan de } \\
\text { Achuriaga }\end{array}$ & Beata \\
\hline \multirow{3}{*}{1664} & Teresa de Jesús & Comendadora \\
\hline & María de la Cruz & Vicaria \\
\hline & Evangelista de Ballido & Beata \\
\hline \multirow[b]{3}{*}{1666} & Teresa de Jesús & Comendadora \\
\hline & María de la Cruz & Vicaria \\
\hline & $\begin{array}{c}\text { Catalina de San Lorenzo, } \\
\text { Concepción de los Oyos, } \\
\text { Catalina del Valle, Bautista } \\
\text { de Balparda, María de } \\
\text { San Miguel, Águeda de } \\
\text { Mendieta }\end{array}$ & Beatas \\
\hline 1667 & Teresa de Jesús & Comendadora \\
\hline \multirow[t]{2}{*}{1674} & Asunción de Mendieta & Comendadora \\
\hline & María de la Cruz & Vicaria \\
\hline 1676 & Catalina del Valle & Beata \\
\hline 1685 & Martina del Valle & Beata novicia \\
\hline 1702 & Teresa de Jesús y Retuerto & Beata \\
\hline 1711 & Josefa Balparda & Beata novicia \\
\hline \multirow{4}{*}{1712} & $\begin{array}{c}\text { Bernarda Evangelista del } \\
\text { Puerto }\end{array}$ & Comendadora \\
\hline & Ana de la Cruz y Nozedal & Vicaria \\
\hline & $\begin{array}{c}\text { María del Espíritu Santo } \\
\text { y Pérez }\end{array}$ & Beata \\
\hline & $\begin{array}{c}\text { Josefa de San Jose y } \\
\text { Balparda }\end{array}$ & Beata \\
\hline \multirow{3}{*}{1713} & $\begin{array}{c}\text { María del Espíritu Santo } \\
\text { y Pérez }\end{array}$ & Comendadora \\
\hline & $\begin{array}{c}\text { Ana de la Cruz y Nocedal, } \\
\text { Evangelista del Puerto, } \\
\text { Josefa de San José y } \\
\text { Balparda }\end{array}$ & \\
\hline & Francisca del Balle & Beata novicia \\
\hline \multirow[b]{2}{*}{1714} & $\begin{array}{c}\text { María del espíritu Santo } \\
\text { y Pérez }\end{array}$ & Comendadora \\
\hline & $\begin{array}{c}\text { Ana de la Cruz y Nocedal, } \\
\text { Bernarda Evangelista de } \\
\text { Puerto }\end{array}$ & Beata \\
\hline 1718 & $\begin{array}{c}\text { Ana María de Santa Rosa y } \\
\text { Nocedal }\end{array}$ & Beata novicia \\
\hline \multirow[b]{2}{*}{1720} & Francisca del Balle & Comendadora \\
\hline & $\begin{array}{c}\text { Ana de la Cruz, Evangelista } \\
\text { de Puerto San Joseph de } \\
\text { Valparda y Santa Rosa de } \\
\text { Nozedal }\end{array}$ & Beatas \\
\hline 1728 & María Trinidad de Pucheta & Beata novicia \\
\hline
\end{tabular}




\begin{tabular}{|c|c|c|}
\hline Año & Identidad & Cargo \\
\hline & Rosa de Nocedal & Comendadora \\
\hline 1744 & $\begin{array}{l}\text { San Joseph de Balparda, } \\
\text { María de Trinidad, San } \\
\text { Pedro de las Heros, } \\
\text { san Ramón de Revilla y } \\
\text { Francisca de Mercedes y } \\
\text { Nozedal }\end{array}$ & \\
\hline 1751 & María Aresti & Beata novicia \\
\hline \multirow{6}{*}{1753} & Gregoria de San Pedro & Comendadora \\
\hline & María Trinidad de Pucheta & \multirow{5}{*}{ Beata } \\
\hline & $\begin{array}{c}\text { Antonia de San Ramon y } \\
\text { Rebilla }\end{array}$ & \\
\hline & $\begin{array}{c}\text { Josefa de San Jose y } \\
\text { Balparda }\end{array}$ & \\
\hline & $\begin{array}{c}\text { Francisca Mercedes y } \\
\text { Nozedal }\end{array}$ & \\
\hline & $\begin{array}{c}\text { María de San Antonio y } \\
\text { Aresti }\end{array}$ & \\
\hline \multirow[b]{2}{*}{1786} & Ramona de Rebilla & Comendadora \\
\hline & $\begin{array}{c}\text { Francisca del Corazón de } \\
\text { Jesús y García }\end{array}$ & Beata novicia \\
\hline \multirow{4}{*}{1787} & $\begin{array}{c}\text { Francisca del Corazón de } \\
\text { Jesús y García }\end{array}$ & Comendadora \\
\hline & $\begin{array}{l}\text { Antonia de San Ramón y } \\
\text { Rebilla }\end{array}$ & \multirow{3}{*}{ Beata } \\
\hline & Brígida de Jesús y el Valle & \\
\hline & $\begin{array}{l}\text { Agustina de San José y } \\
\text { Saneciación }\end{array}$ & \\
\hline 1788 & $\begin{array}{c}\text { Francisca del Corazón de } \\
\text { Jesús y García }\end{array}$ & Comendadora \\
\hline \multirow[t]{2}{*}{1790} & $\begin{array}{c}\text { Agustina de San José y San } \\
\text { Martín }\end{array}$ & Comendadora \\
\hline & Brígida de Jesús y el Valle & Secretaria \\
\hline
\end{tabular}

Fuente: elaboración propia a partir de datos en AHPB, Francisco Javier de Ibarra 7078/4, 7078/5, 7079/1, 7080/1; Simón Pucheta 4868, 5579/2, 7094/2, 7287/1, 7287/2; Francisco de Oyanzas y Nocedal 5916/5, 7071/1, 7071/2; Pedro Oyanzas y Zuazo 7073/5, 7073/9, 7073/7, 7074/4; Matías de Villar 4796, 7054, 7066/2; Francisco Villar y Cotillo 5926/2, 7064/3; Juan Ángel de Zuazo 7067/5; Diego Zubiete 4797/4.
TABLA 4

Los censos

\begin{tabular}{|c|c|c|c|}
\hline $\begin{array}{c}\text { Fecha } \\
\text { fundación }\end{array}$ & $\begin{array}{l}\text { Fecha carta } \\
\text { de pago }\end{array}$ & Fundador & Cantidad \\
\hline- & - & - & $\begin{array}{l}100 \text { ducados de } \\
\text { vellón }\end{array}$ \\
\hline 1613 & 1712 & $\begin{array}{l}\text { Pedro de Nocedal y } \\
\text { María de Samudo, } \\
\text { vecinos de } \\
\text { Portugalete }\end{array}$ & 35 ducados de vellón \\
\hline- & 1676 & - & 70 ducados de vellón \\
\hline 1619 & 1674 & $\begin{array}{l}\text { Pedro de la Ormaza } \\
\text { menor, vecino de } \\
\text { Santurce, y heredero } \\
\text { de Juan de Pucheta, }\end{array}$ & $\begin{array}{l}100 \text { ducados de } \\
\text { vellón }\end{array}$ \\
\hline 1623 & 1667 & Sancho de Oyanzas & 50 ducados de vellón \\
\hline 1650 & - & Francisco de Murrieta & 256 reales \\
\hline 1655 & - & $\begin{array}{c}\text { Antonio de la Hera y } \\
\text { Ana de Zuazo, vecinos } \\
\text { de Sestao }\end{array}$ & 100 ducados \\
\hline 1665 & - & $\begin{array}{c}\text { Marcos de las Tres y } \\
\text { Catalina de la Sierra } \\
\text { como principales y } \\
\text { Domingo de la Sierra } \\
\text { como fiador }\end{array}$ & $\begin{array}{l}200 \text { ducados de } \\
\text { vellón }\end{array}$ \\
\hline 1685 & - & Juan del Valle & $\begin{array}{l}250 \text { ducados de } \\
\text { vellón }\end{array}$ \\
\hline- & 1688 & & $\begin{array}{l}100 \text { ducados de } \\
\text { vellón }\end{array}$ \\
\hline 1700 & 1790 & & 25 ducados de vellón \\
\hline 1702 & 1710 & $\begin{array}{l}\text { Juan de Collado, } \\
\text { vecino de Portugalete }\end{array}$ & 25 ducados de vellón \\
\hline 1711 & - & Josefa de Umaran & $\begin{array}{l}250 \text { ducados de } \\
\text { vellón }\end{array}$ \\
\hline 1713 & - & - & $\begin{array}{l}300 \text { ducados de } \\
\text { vellón }\end{array}$ \\
\hline 1728 & - & $\begin{array}{l}\text { Pedro de Pucheta } \\
\text { y Agustina de } \\
\text { Sarachaga, vecinos de } \\
\text { Santurce }\end{array}$ & $\begin{array}{l}125 \text { y } 175 \text { ducados } \\
\text { de vellón }\end{array}$ \\
\hline 1731 & 1787 & - & $\begin{array}{l}100 \text { ducados de } \\
\text { vellón }\end{array}$ \\
\hline 1786 & - & - & $\begin{array}{l}500 \text { ducados de } \\
\text { vellón }\end{array}$ \\
\hline- & 1788 & - & 74 ducados de vellón \\
\hline
\end{tabular}

Fuente: elaboración propia a partir de datos en AHPB, Francisco Javier Ibarra 7078/4, 7078/5. 7079/1, 7080/1; Francisco Oyanzas y Nocedal 5916/5, 7070/1, 7071/2,7071/6; Pedro de Oyanzas y Zuazo 7073/5, 7073/7, 7074/4; Simón Pucheta 7094/1, 7287/1, 7287/2; Francisco Villar y Cotillo 5926/2, 7064/3; Diego Zubiete 4797/4 


\section{FUENTES}

Archivo Histórico Provincial de Bizkaia [AHPB]

Archivo Foral de Bizkaia [AFB]

Archivo Histórico Eclesiástico de Bizkaia [AHEB]

Archivo Franciscano Ibero-Oriental [AFIO]

Archivo del Convento de San Antonio de Durango [ACSAD]

Archivo del Convento de Santa Clara de Gernika [ACSCG]

Archivo del Convento de Santa Clara de Portugalete [ACSCP]

Boletín de la Orden de la Merced, año XVII, no1-2, 1930, p.12.

\section{BiBLIOGRAFÍA}

Álvarez Rodríguez, A. 2015. «De beatas a monjas dominicas: el proceso de constitución del monasterio de Santa Catalina de Sena de Zamora a finales del siglo XV». Hispania LXXV (249): 11-38. https:// doi.org/10.3989/hispania.2015.001

Arana, M. J. 2002. "La mujer vasca en la vida religiosa de Euskal Herria», en J. Intxausti (ed.), Historia de los Religiosos en el País Vasco y Navarra. Aránzazu: Editorial Franciscana Arantzazu.

Arias González, J. 2007. Los místicos sabores del convento: las monjas urbanistas y sus hábitos alimentarios en Querétaro (siglos XVII-XVIII). México: Consejo del IV Centenario de la Fundación de Convento de Santa Clara de Jesús.

Atienza López, A. 1991. "Transformaciones en el sistema de crédito y crisis de las economías monásticas en Aragón a fines de Antiguo Régimen ». Revista de Historia Económica IX (3): 499-511. https://doi.org/10.1017/s0212610900003037

Atienza López, A. 2007. «De beaterios a conventos: nuevas perspectivas sobre el mundo de las beatas en la España moderna». Historia social 57: 145-168.

Atienza López, A. 2008. Tiempos de conventos. Una historia social de las fundaciones en la España moderna. Madrid. Marcial Pons.

Atienza López, A. 2014. «Las grietas de la clausura tridentina. Polémicas y limitaciones de las políticas de encerramiento de las monjas... Todavía con Felipe IV». Hispania LXXIV (248): 807-834. https://doi. org/10.3989/hispania.2014.024

Barrio Gozalo, M. 2002. La sociedad en la España Moderna. Madrid: Cuadernos de Cultura y Civilizaciones Hispánicas.

Biblioteca Mercedaria. 1977. La Orden de Santa María de la Merced (1218-1992), Síntesis histórica. Roma: Instituto Histórico de la Orden de la Merced.

Catalán Martínez, E. 2000. El precio del purgatorio. Ingresos del clero vasco en la Edad Moderna. Bilbao: UPV/EHU.

Catalán Martínez, E. 2004. «El derecho de patronato y el régimen beneficial de la iglesia española en la Edad Moderna». Hispania Sacra 56 (113): 135-168. https://doi.org/10.3989/hs.2004.v56.i113.147

Celaya Ibarra, A. 2005. "La Reforma de 1506. Un documento clave en nuestra historia foral». Jado. Boletín de la Academia Vasca de Derecho 3 (5).

Curiel Yarza, I. 2009. La parroquia en el País Vasco-cantábrico durante la Baja Edad Media (1350-1530). Bilbao: Universidad del País Vasco.

Dacosta Martínez, A. 1999. «Patronos y linajes en el Señorío de Bizkaia. Materiales para una cartografía del poder en la Baja Edad Media». Vasconia. Cuadernos de Sección de Historia-Geografía. EuskoIkaskuntza 29: 21-46.

Dacosta Martínez, A. 2001. «Porque el fasía desafuero. La resistencia estamental al corregidor en la Bizkaia del siglo XV», en R. Porres Marijuán (ed.), Poder, resistencia y conflicto en las Provincias Vascas, siglos XV-XVIII: 37-64. Bilbao: UPV/EHU.

Díaz de Durana, J. R. 1998. «Patronatos, patronos, clérigos y parroquianos. Los derechos de patronazgo sobre monasterios e iglesias como fuente de renta e instrumento de control y dominación de los Parientes Mayores guipuzcoanos, siglos XIV a XVI». Hispania Sacra L (102): 467-508. https://doi.org/10.3989/hs.1998.v50.i102.617

Domínguez Ortiz, A. 2000. «Juros y censos en la Castilla del seiscientos: una sociedad de rentistas», en A. M. Bernal (ed.), Dinero, moneda y crédito en la Monarquía Hispánica: 789-806. Madrid: Fundación Marcial Pons.

Espinosa Soriano, W. y Baltasar Olmeda, M. 2010. «Los beaterios en la Lima colonial. El caso de un beaterio para mujeres indígenas nobles». Investigaciones sociales 14 (24): 131-147.

Evangelisti, S. 2007. Nuns. A history of convent life, 1450-1700. Oxford: Oxford University Press.

Frohnapfel, M. 2013. "Zamora y el Concilio de Trento. Una aportación a conventos y beaterios femeninos», en M. Ramos Medina (coord.), Vida conventual femenina (siglos XVI-XIX): 475-486. México: Fundación Carlos Slim.

García Fernández, E. 1995. «Dominicos y franciscanos en el País Vasco (siglos XIII-XV)», en VI Semana de Estudios medievales. Logroño: Instituto de Estudios riojanos.

García Fernández, E. 2007. «Iglesia, religiosidad y sociedad en el País Vasco durante el siglo XIV». Edad Media. Revista de historia 8: 99-144.

Gastañazpi, E. 1994. «Redes eclesiásticas diocesanas en el País Vasco, siglos XIV-XVI», en E. García Fernández (ed.), Religiosidad y sociedad en el País Vasco, siglos XIV-XVI. Bilbao: UPV/EHU.

Intxaustegi Jauregi, N. J. 2014. «Celebraciones en torno a la clausura de los conventos bilbaínos en el siglo XVII». Bidebarrieta: Revista de humanidades y ciencias sociales de Bilbao 25: 48-56.

Intxaustegi Jauregi, N. J. 2015. «La rebelión de las clarisas vizcaínas frente al Concilio de Trento», en F. Labrador (ed.), II Encuentro de Jóvenes Investigadores en Historia Moderna. Líneas recientes de investigación en Historia Moderna: 93-105. Madrid: Ediciones Cinca.

Intxaustegi Jauregi, N. J. 2017a. «Beatas, beaterios and convents: the origin of the Basque female conventual life». Imago Temporis. Medium Aevum XI: 329-341. https://doi.org/10.21001/itma.2017.11.13

Intxaustegi Jauregi, N. J. 2017b. "La presencia de la Orden de San Agustín en Bilbao». Analecta Agustiniana LXXX: 167-184.

Intxaustegi Jauregi, N. J. 2018a. «Beatas y beaterios vizcaínos: desde el nacimiento medieval hasta la extinción en el siglo XIX», en Actas de la XIV Reunión de la Fundación Española de Historia Moderna: 1149-1165. Zaragoza.

Intxaustegi Jauregi, N. J. 2018b. "Convents: the image of the Basque patronage network power», en K. Smith (ed.), Monastic Europe AD 1100-1700: Landscape and settlement. Dublin: Brepols.

Intxaustegi Jauregi, N. J. 2018c. La mujer religiosa en Bizkaia durante los siglos XVI-XVIII, Bilbao: Diputación Foral de Bizkaia.

Iturriza Zabala, J. R. 2000. Historia General de Vizcaya, Barcelona: Edición facsimilar

Labayru, E. 1968. Historia General del Señorío de Bizcaya. Bilbao: Biblioteca de la Gran Enciclopedia Vasca, Tomo IV.

Lafarga Lozano, A. 1970. «Noticia de los Reales Patronatos del Señorío de Vizcaya». Hidalguía 103.

Laka Kortabitarte, J. 2002. "Presencia mercedaria en el País Vasco y Navarra», en J. Intxausti, (ed.), Historia de los Religiosos en el País Vasco y Navarra, vol. I: 456-472. Aránzazu: Editorial Franciscana.

Larrea Beobide, A. 2001. El Patronato laico vizcaíno en el Antiguo Régimen. Bilbao: Beta III Milenio.

Ledesma, F. 1709: Historia breve de la fundación del convento de la Purísima Concepción de Maria Santisima de Mercedarias Descalzas.

Lizarralde, J. A. 1918. "Orígenes de la vida claustral en el País Vasco», en I Congreso de Eusko Ikaskuntza. Oñate.

López Atxurra, R. 2000. "Historia de las instituciones educativas en Euskal Herria. La enseñanza primaria en el Antiguo Régimen. Pautas para la investigación», en R. Mieza y J. Gracia (eds.), Haciendo Historia. Homenaje a $M^{\underline{a}}$ Ángeles Larrea: 419-446. Bilbao: UPV-EHU.

Madariaga Orbea, J. 2014. Sociedad y lengua vasca en los siglos XVII y XVIII. Bilbao: Euskaltzaindia.

Madres Mercedarias Monasterio de San José. Lañomendi, Loiu, Bilbao. 2017. Monjas de la Orden de Santa María de la Merced. Bilbao: Ediciones Delia. 
Makowski, E. 1997. Canon law and cloistered women. Periculoso and its Commentators. 1298-1545. Washington, D.C.: The Catholic University of America Press.

Mira Caballos, E. y Villa Nogales, F. de la 1999. Carmona en la Edad Moderna: religiosidad y arte, población y emigración a América. Brenes: Muñoz Moya.

Negredo del Cerro, F. 2005. «La propiedad inmobiliaria en el Madrid Moderno: transformación social y cortesanización de un espacio urbano", en P. Lavastre y R. Mas (ed.), Propiedad urbana y cre cimiento de la ciudad. Seminario celebrado 4-5 febrero de 2002 13-33. Madrid: Universidad Autónoma de Madrid.

Ortega Berruguete, A. R. 1990. «Demografía vasca a fines del Antiguo Régimen. Análisis de la población de Bizkaia, Gipuzkoa y Araba a través del Censo de 1787». Cuadernos de Sección. HistoriaGeografía 17: 174-207.

Paz Moro, A. 2017. San Juan de Quejana, un monasterio familiar de dominicas en el Valle alavés de Ayala (1378-1525). Sus vínculos con el linaje de Ayala. Bilbao: Universidad del País Vasco.

Pérez Álvarez, M. J. 2014. "Las franciscanas leonesas en la Edad Moderna». Sémata, Ciencias Sociais e Humanidades 26: 221-245.

Pi Corrales, M. P. 2010. «Existencia de una monja: vivir el convento, sentir la Reforma (siglos XVI-XVII)». Tiempos Modernos 20.

Prada Camín, M. F. 2013. Ocho siglos de Historia de las clarisas en España. Murcia: Publicaciones Instituto Teológico de Murcia OFM.

Rapley, E. 1990. The dévotes. Women and church in seventeenth-century France. McGill-Queen's Studies in the History of Religion.

Reguera, I. y Angulo Morales, A. 2004. «La(s) imagen(es) de los vascos», en Historia del País Vasco, Edad Moderna (siglos XVI-XVIII). San Sebastián: Alegia, Editorial Hiria.

Rey Castelao, O. 2009. «Las instituciones monásticas femeninas, ¿centros de producción?». Manuscrits: Revista d'històire moderna 27: 59-76.

Rey Castelao, O. 2011. "Amour divin et amour mondain: I'experiénce des femmes mariées et de veuves en religion dans la Galice modern. Les beaterios et couvents de la Galice, XVle-XVIIle siècles», en M. Daumas (ed.), Amour divin, amour mondain dans les écrits du for privé de la fin de Moyen Age à 1914. Pau: Cairn.

Rodríguez Condado, E. 1994. Monasterio de la Santa Cruz: Bilbao, Begoña, Lujua. Bilbao: Gráficas Alustiza.

Rodríguez Condado, E. 1995. Monasterio de la Concepción de Abando. Bilbao: Gráficas Alustiza.

Rodríguez Condado, E. 1997. Monasterio de San Antonio de Durango. Bilbao: Gráficas Alustiza.

Rodríguez Condado, E. 1998. Monasterio de Santa Clara de Portugalete. Bilbao: Gráficas Alustiza.
Rodríguez Condado, E. 2000. Monasterio de Santa Clara: Abando, Begoña, Bilbao y Derio. Bilbao: Gráficas Alustiza.

Rodríguez Duarte, M. C. 2017. «Los conventos femeninos de Sanlúcar: un universo de movilidad e intercambios». e-Spania 26. https:// doi.org/10.4000/e-spania.26256

Roest, B. 2013. Order and disorder. The Poor Clares between Foundation and reform. Leiden: Brill.

Sastre Santos, E. 1996. "Condición jurídica de beatas y de beaterios. Introducción y textos, 1139-1917». Anthologica annua 43: 287-586.

Serrano Estrella, F. 2007. «Encuentros y desencuentros entre las cofradías y los conventos de la ciudad de Jaén en la Edad Moderna». Elucidario 3: 301-310.

Soriano, C. 2000a. «La propiedad inmobiliaria de los conventos femeninos madrileños en el siglo XVIII». Cuadernos de Historia Moderna 24: 11-29.

Soriano, C. 2000b. «Trento y el marco institucional de las Órdenes religiosas femeninas en la Edad Moderna». Hispania Sacra 52 (106): 479-494. https://doi.org/10.3989/hs.2000.v52.i106.565

Strocchia, S. T. 2009. Nuns and nunneries in Renaissance Florence. Baltimore: The John Hopkins University Press.

Uribe, A. 1994. «Asentamientos y expansión de la orden de Santa Clara en el País Vasco». Revista Archivo Ibero-Americano 54 (213-214): 233-256.

Uribe, A. 1998. La Provincia Franciscana de Cantabria. Arantzazu: Editorial Franciscaza.

Val Valdivieso, I. del 1986. "Vizcaya frente al obispo de Calahorra», en Simposio Nacional sobre Ciudades episcopales. Zaragoza: Institución Fernando el Católico.

Val Valdivieso, I. del 2006. "La identidad urbana al final de la Edad Media». Revista Internacional de la Europa Atlántica en la Edad Media 1: 5-28.

Van Engen, J. 2008. Sisters and Brothers of the Common Life. The Devotio Moderna and the World of the Later Middle Ages. Philadelphia: University of Pennsylvania.

Viforcas Marinas, M. I. 1993. «El beaterio quiteño de Nuestra Señora de la Merced y sus fallidos intentos de transformación en Convento (1730-1758)», en M. I. Viforcas Marinas y J. Paniagua Pérez (coords.), I Congreso Internacional del Monacato femenino en España, Portugal y América, Vol. II: 357-366. León: Servicio de Publicaciones de la Universidad de León.

Vigil, M. 1998. La vida de las mujeres en los siglos XVI y XVII. Madrid: Editorial Siglo XXI. 